\title{
Revista
}

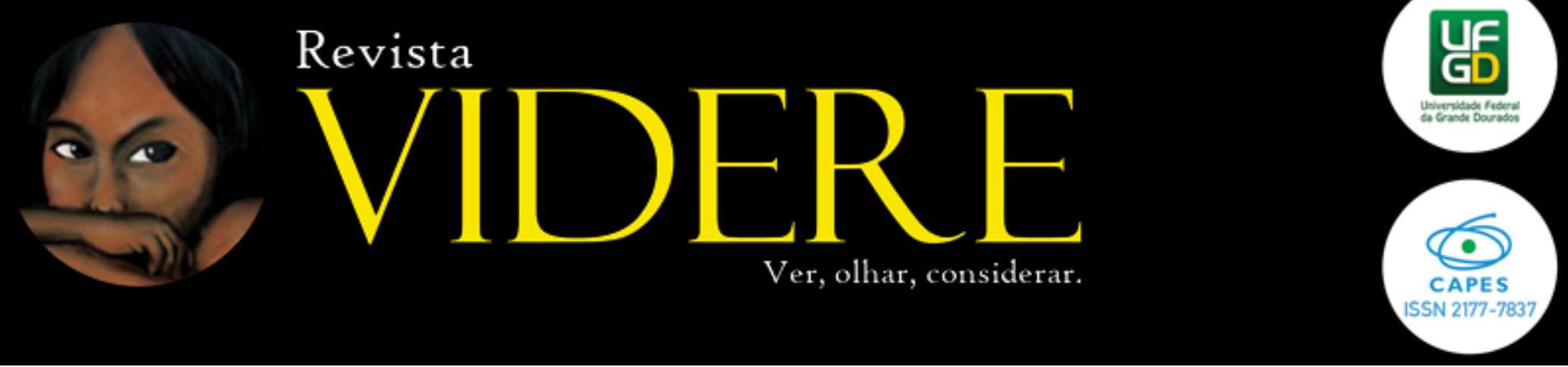

\section{A interpretação da decisão jurídica advinda da ADPF 132 e da ADI 4.277, segundo a perspectiva de Castanheira Neves: a decisão e suas consequências jurídicas do}

\section{The interpretation of judgment resulting of ADPF132 and ADI 4277 according to Castanheira Neves's theory: the judgment and it's juridical consequences}

\author{
Paulo Henrique Borges da Rocha (iD) \\ Doutor em Direito Público Internacional pela (PUC-MG) \\ Centro Universitário de Lavras (UNILAVRAS) \\ Lavras, Minas Gerais, Brasil \\ E-mail: paulo-borges@live.com
}

\author{
Alexandre Gustavo Melo Franco Bahia \\ Doutor em Direito Constitucional (UFMG) \\ Universidade Federal de Ouro Preto (UFOP) \\ Ouro Preto, Minas Gerais, Brasil \\ E-mail: alexprocesso@gmail.com
}

\begin{abstract}
Resumo: O artigo trata do julgamento da ADPF 132/ADI 4.277 no qual o Supremo Tribunal Federal procedeu a uma interpretação conforme a Constituição para equiparar as uniões entre pessoas do mesmo sexo às demais uniões estáveis. Houve grande debate não apenas no Tribunal, com a participação de vários "amici curiae", mas também na imprensa e em vários fóruns de discussão. Os fundamentos do STF foram os princípios da igualdade e da não discriminação, além do histórico jurisprudencial a favor da equiparação de vários Tribunais inferiores. Tal concepção principiológica do Direito (e da Constituição em particular) encontra eco na teoria de Castanheira Neves, o estudioso traz em sua teoria uma forma de interpretar a decisão jurídica, tendo uma perspectiva ampla do que vem a ser o sistema jurídico e como deve ocorrer essa interpretação, não restringido o direito apenas ao texto legal, em sua teoria são os princípios que conferem sentido ao direito, ele pensou uma metodologia para a utilização da hermenêutica na interpretação das decisões jurídicas. É feito um breve relato sobre os casos, depois, apontam-se alguns fundamentos do jurisprudencialismo de Castanheira Neves, para, então, interpretar a decisão a partir de tal teoria e concluir que o STF, desvencilhando-se de uma exegese literal dos textos, se valeu de princípios normativos, lidos a partir da consciência jurídica geral, o que permitiu fosse feita analogia com as uniões estáveis heteroafetivas já previstas na lei civil.
\end{abstract}

Palavras-chave: União homoafetiva. STF. ADPF 132. Castanheira Neves. Analogia.

\begin{abstract}
The paper deals with judgment of ADPF 132 / ADI 4277 in which the Brazilian Supreme Court carried out an interpretation according to Constitution to equate unions between same-sex partnerships to the other stable unions. There was considerable debate not merely in court, with participation of several "amici curiae", but also in media and in various discussion boards. The grounds of the Brazilian Supreme Court were the principles of equality and non-discrimination, in addition to historical case law in favour of assimilation of various lower courts. This principled theory of law (and the Constitution in particular) meets with response among Castanheira Neves's theory. The scholar brings in his theory a particular way of interpreting the legal decision, taking a broad perspective of what comes to the legal system and how that interpretation should occur not only restricted the right to legislative text, in his theory are the principles that provide the right sense, he thought own methodology for the use of hermeneutics for the interpretation of legal decisions. In the article it made a brief report on the case cited, then, are pointed some fundamentals of Castanheira Neves's theory, to interpret the decision and concluded that the Brazilian Supreme Court, shifting away from an exegesis of literal texts, drew upon normative principles, read from the general legal consciousness, which was made possible analogy with stable heterosexual unions already provided in civil law.
\end{abstract}

Keywords: Same-sex partnerships. Brazilian Supreme Court. ADPF 132. Castanheira Neves. Analogy. 


\section{Introdução}

O julgamento da ADPF 132 e da ADI 4.277 foi um marco contra a discriminação oriunda da orientação sexual do indivíduo. Esse julgamento, ocorrido em maio de 2011, mobilizou não só o Supremo Tribunal Federal, mas toda a sociedade brasileira. Os Ministros ponderaram, à luz dos princípios do direito, sobre a equiparação da união homoafetiva com a união estável e sobre a possibilidade de garantir o status de entidade familiar para elas.

Ao final dessas ações que foram julgadas conjuntamente por terem praticamente o mesmo objeto, os Ministros deram procedência ao pedido, equiparando as uniões homoafetivas às uniões estáveis, bem como garantindo-Ihes o status de entidade familiar.

Ao conferirem essa equiparação entre as uniões, os Ministros, além de proibir esse tipo de discriminação, reforçaram a construção de uma perspectiva nova sobre o Direito, principalmente sobre o Direito de Família, que já vinha sendo feita há algum tempo pelos Tribunais inferiores e também pela doutrina no Brasil.

Pelo impacto e importância que essa decisão teve, é imprescindível entender como ocorreu tal julgamento e interpretar a decisão jurídica que se originou com as referidas ações, visualizando se a decisão foi acertada e verificando os efeitos da mesma no âmbito jurídico.

Para interpretar a decisão jurídica no presente trabalho, foi utilizada a metodologia de Castanheira Neves. Essa metodologia permite que entendamos todo o processo de criação de uma decisão jurídica, além de possibilitar interpretar suas consequências no âmbito jurídico.

Mesmo havendo vários estudos sobre essas ações, o estudo aqui presente vai por um viés distinto, não apenas procurando a resposta sobre se os Ministros acertaram ou não em suas decisões, mas tentando também entender a decisão final e sua consequência para o direito. Para tanto, inicialmente foi trazido o que ocorreu no julgamento e como os Ministros chegaram à decisão unânime pela procedência do pedido. Posteriormente, foram trazidas para a discussão as ideias de Castanheira Neves, para que, por fim, houvesse uma interpretação segundo a metodologia criada pelo estudioso.

A relevância deste estudo é indiscutível, visto que a decisão jurídica utilizada para fundamentá-lo consolidou uma construção hermenêutica ${ }^{1}$ há algum tempo já desenvolvida do que vem a ser entidade familiar, e, por ser a família a base da sociedade - tal como dito na Constituição Federal -, gerou um impacto direto e

\footnotetext{
${ }^{1}$ Utilizamos aqui a ideia de "interpretação construtiva" segundo Dworkin. Dworkin (1999) parte da ideia de integridade no Direito como medida de garantia de que cada decisão gere, ao mesmo tempo, segurança jurídica e aceitabilidade racional. As proposições jurídicas, então, serão verdadeiras se, ao interpretarem o direito, reconstruindo-o procedimentalmente no presente, voltem-se para o passado (tomado reflexivamente) e para o futuro (como abertura e respeito às futuras gerações). Aí aparece a ideia de "interpretação construtiva": o direito não é um amontoado de normas e decisões do passado, mas forma um todo coerente - essa coerência é (re)construída pelo juiz, até para, eventualmente, mostrar que a decisão passada já não atende aos princípios de justiça, equanimidade e devido processo legal tal qual os concebemos no presente. Segundo Dworkin (Ibidem., p. 274), "[as] declarações de direitos são permanentemente construtivas, em virtude de sua própria natureza". A interpretação construtiva buscará princípios válidos a partir dos quais seja possível justificar uma ordem jurídica concreta, de modo que nela se encaixem todas as decisões como se fossem componentes coerentes (retiradas, é claro, aquelas que possuem erros) (Ibidem. p. 305), o que, ao final, Ihe fornecerá a única resposta correta para o caso. Para explicar melhor esse procedimento, o autor se vale da metáfora do "romance em cadeia": o autor seguinte escreve um capítulo que é novo, mas que deve guardar coerência com os anteriores (Ibidem. p. 287ss). Os juízes, de forma similar aos escritores do romance, são, ao mesmo tempo, autores (porque acrescentam algo) e críticos (porque interpretam) das tradições que resgatam.
} 
imediato, trazendo dúvidas sobre a possibilidade de casamento civil homoafetivo. Sem embargo dessa questão "técnica" mais imediata, há outros desdobramentos mais profundos sobre as consequências de tal decisão para o sistema jurídico. Sem o intuito de findar a discussão sobre o tema, menos ainda de dar uma resposta incontestável, o presente estudo buscou trazer à tona uma nova forma de análise sobre as referidas decisões.

\section{0 julgamento da ADPF 132/RJ e da ADI 4.277/DF}

A equiparação da união homoafetiva à união estável foi tema da ADPF 132/RJ, tendo seu julgamento ocorrido no dia cinco de maio de 2011. O julgamento resultou na equiparação da união homoafetiva à união estável, prevista na Constituição Federal, e reconheceu o status de entidade familiar deste tipo de relacionamento afetivo. Essas ações tiveram a participação de quatorze amicus curiae, por ser um tema complexo e relevante. A decisão foi de procedência, por votação unânime dos Ministros do Supremo Tribunal Federal (estando impedido o Ministro Dias Toffoli, por ter atuado como Advogado-Geral da União em um dos processos). A decisão teve efeito erga omnes e vinculante para toda a Administração Pública e aos demais órgãos do Poder Judiciário.

Protocolizada e autuada no dia vinte e sete de fevereiro de 2008, a Arguição de Descumprimento de Preceito Fundamental de número 132 - ADPF 132 - foi proposta pelo Governador do Rio de Janeiro - Sérgio Cabral -, alegando que a diferenciação entre os dois tipos de união afetiva violaria aos seguintes preceitos fundamentais: Princípio da igualdade (Art. 5ำ, caput da Constituição Federal); Princípio da liberdade \{princípio esse que deriva o princípio da autonomia da vontade\} (Art. 5º, Il da Constituição Federal); Princípio da dignidade da pessoa humana (Art. 1ํㅡㄴ III da Constituição Federal); e o Princípio da segurança jurídica (Art. 5º, caput da Constituição Federal). Sustentando como fatos geradores de tais descumprimentos por parte do Poder Público, a interpretação discriminatória conferida aos incisos II e V do artigo $19^{2}$ e os incisos I a X e parágrafo único do artigo 33³, ambos do Decreto-Lei 220/1975 (Estatuto dos Servidores Civis do Estado do Rio de Janeiro), com relação aos parceiros homossexuais, bem como a prolação de decisões judiciais negando a equiparação jurídica das uniões estáveis homoafetiva àquelas protagonizadas por casais heterossexuais. Com isso, o autor pediu procedência ao pedido com o intuito de estender a aplicação da união estável também para as uniões homoafetiva (que cumpram os requisitos da união estável), por meio da interpretação conforme a Constituição ${ }^{4}$, do artigo 1.723 do Código Civil de 2002, bem como a interpretação dos artigos 19, II e V e 33, I a X e parágrafo único do Decreto-Lei 220/1975, como decorrência dos preceitos fundamentais supracitados, ou,

\footnotetext{
2 BRASIL. Decreto-Lei n. 220/1975. Art. 19. Conceder-se-á licença: [...] II - por motivo de doença em pessoa da família, com vencimento e vantagens integrais nos primeiros 12 (doze) meses; e com dois terços, por outros 12 (doze) meses, no máximo; [...] V - Sem vencimento, para acompanhar o cônjuge eleito para o Congresso Nacional ou mandado servir em outras localidades se militar, servidor público ou com vínculo empregatício e empresa estatal ou particular.

${ }^{3}$ BRASIL. Decreto-Lei n. 220/1975. Art. 33. O poder Executivo disciplinará a previdência e a assistência ao funcionário e à sua família, compreendendo: I - Salário-família; II - Auxílio-doença; III - Assistência médica, farmacêutica, dentária e hospitalar; IV - Financiamento imobiliário; V - Auxílio-moradia; VI - Auxílio para a educação dos dependentes; VII - Tratamento por acidente em serviço, doença profissional ou internação compulsória para tratamento psiquiátrico; VIII - Auxílio-funeral, com base no vencimento, remuneração ou provento; IX - Pensão em caso de morte por acidente em serviço ou doença profissional; $\mathrm{X}$ - Plano de seguro compulsório para complementação de proventos e pensões. Parágrafo único - A família do funcionário constitui-se dos dependentes que, necessária e comprovadamente, vivam a suas expensas.

${ }^{4}$ A interpretação constitucional, como a interpretação jurídica em geral, não é um exercício abstrato de busca de verdades universais e atemporais. Toda interpretação é produto de uma época, de um momento histórico, e envolve as normas jurídicas pertinentes, os fatos a serem valorados, as circunstâncias do intérprete e o imaginário social. [...]É hoje pacífico que o papel do intérprete não é - porque não pode ser - apenas o de descobrir e revelar a solução que estaria abstratamente contida na norma. Diversamente, dentro das possibilidades e limites oferecidos pelo ordenamento, a ele caberá fazer, com frequência, valorações in concreto e escolhas fundamentadas (BARROSO, 2007, p. 5).
} 
alternativamente, pelo reconhecimento da existência de uma lacuna normativa que deve ser integrada analogicamente, uma vez que, os elementos essenciais para se constituir uma união estável encontram-se presentes tanto nas uniões entre pessoas de sexos distintos, quanto nas uniões de pessoas de mesmo sexo, de acordo com a redação do referido artigo, que traz como elementos essenciais para a união estável a convivência pública, contínua e duradoura, cujo objetivo é a constituição da família.

O autor fez um pedido subsidiário de que, caso o Supremo Tribunal Federal não decidisse pela procedência do pedido da ADPF, a ação pudesse ser conhecida como Ação Direta de Inconstitucionalidade $A D I$ - de modo que se conceda uma interpretação conforme a Constituição dos referidos dispositivos legais, com o intuito de impedir uma interpretação que excluísse os servidores homoafetivos da tutela jurídica. Esse pedido foi acatado pelo Ministro Relator Ayres Britto que, baseando em precedentes da Corte ${ }^{5}$, desmembrou a ADPF 132 e criou a ADI 4.277, por ter o objeto da ação mais pertinência com os pressupostos jurídicos da ação direta de inconstitucionalidade.

A ADI 4.277/DF foi proposta no dia dois de julho de 2009 pela Procuradoria Geral da República, tendo sido instruída com cópia da representação apresentada pelo Grupo de Trabalho de Direitos Sexuais e Reprodutivos da Procuradoria Federal dos Direitos do Cidadão, por pareceres de eminentes juristas e por decisões judiciais contrárias à equiparação das referidas uniões. A ação tinha como argumento central, a possibilidade do reconhecimento da união estável entre pessoas do mesmo sexo, possuindo como foco a aplicação dos seguintes princípios constitucionais: princípio da dignidade da pessoa humana (Art. 1ํㅡ. III da Constituição Federal); Princípio da igualdade (Art. 5ํㅗ caput da Constituição Federal); Princípio da vedação a discriminações odiosas (Art. 3ำ, IV da Constituição Federal) e o Princípio à segurança jurídica (Art. 5ํ, caput da Constituição Federal). Pela coincidência de objetos ${ }^{6}$, a $A D I$ foi redistribuída ao Relator, que decidiu pela encampação dos fundamentos da ADPF 132/RJ por esta, uma vez que seu pedido principal se resumia na declaração do reconhecimento da união homoafetiva como entidade familiar, tendo eles os mesmos deveres e direitos dos companheiros heterossexuais estendidos aos homoafetivos.

A argumentação presente nas duas ações é basicamente idêntica e pautada em princípios constitucionais que asseguram aos cidadãos disfrutar com plenitude seu ideal de "vida boa". Princípios esses que garantem ao cidadão desfrutar seu projeto de vida até mesmo no que tange a dimensão sexual e amorosa. Ao final das ações, igualaram-se os dois tipos de união, conferindo a união homoafetiva o status de entidade familiar.

\subsection{Fundamentos para a decisão final das ações}

Nesse momento, é imprescindível o entendimento de como os Ministros construíram o raciocínio para julgar procedente o pedido de equiparação das uniões homoafetivas com as uniões estáveis.

\footnotetext{
${ }^{5}$ ADPF-QO 72 e ADPF 178.
}

${ }^{6}$ BRASIL, Regimento Interno do Supremo Tribunal Federal, Art. 77-B. "Na ação direta de inconstitucionalidade, na ação direta de inconstitucionalidade por omissão, na ação declaratória de constitucionalidade e na arguição de descumprimento de preceito fundamental, aplica-se a regras de distribuição por prevenção quando haja coincidência total ou parcial de objetos" (Grifos nossos). 
Nas ações, houve a necessidade de descobrir se a sexualidade de um casal seria motivo de diferenciação, analisando se a orientação sexual seria ou não fator de discriminação quando recusado a equiparação da união homoafetiva com a união homossexual. O Ministro Luiz Fux, de forma clara em seu voto, demonstra que é discriminação não equiparar tais uniões, diz ele:

\begin{abstract}
Diante disso, ignorar a existência e a validade jurídica das uniões homoafetivas é o mesmo que as por em situação de injustificada desvantagem em relação às uniões estáveis heterossexuais. Compete ao Estado assegurar que a lei conceda a todos a igualdade de oportunidades, de modo que cada um possa conduzir sua vida autonomamente segundo seus próprios desígnios e que a orientação sexual não constitua óbice à persecução dos objetivos pessoais. O raciocínio se aplica, decerto, em todos os aspectos da vida e não apenas os materiais ou profissionais - sob esse prisma, submeter um indivíduo homossexual ao constrangimento de ter que ocultar seu convívio com o(a) parceiro(a) ou de não poder esperar de suas relações os efeitos legalmente decorrentes das uniões estáveis é, sem dúvida, reduzir arbitrariamente as suas oportunidades. (BRASIL. Supremo Tribunal Federal. ADPF 132/RJ.)
\end{abstract}

Adiante em seu voto, Luiz Fux correlaciona o princípio da igualdade com o direito da autonomia privada, entendendo que o tratamento desigual conferido aos casais homossexuais em relação aos casais heterossexuais viola aquele direito ao submetê-los, contra a sua vontade, a padrões morais majoritariamente estabelecidos. Sendo assim, só a equiparação jurídica desses relacionamentos respeitaria o princípio da igualdade material.

Fazendo uma conexão entre o princípio da igualdade e o princípio da vedação a todo tipo de discriminação (art. 3ํ, IV da Constituição Federal), o Ministro Joaquim Barbosa dispõe que:

Comungo do entendimento do relator, em seu brilhante voto, de que a Constituição Federal de 1988 prima pela proteção dos direitos fundamentais e deu acolhida generosa ao princípio da vedação de todo tipo de discriminação. São inúmeros os dispositivos constitucionais que afirmam e reafirmam o princípio da igualdade e da vedação da discriminação, como todos sabemos. Como já tive oportunidade de mencionar, a Constituição Federal de 1988 fez uma clara opção pela igualdade material ou substantiva, assumindo o compromisso de extinguir ou, pelo menos, de mitigar o peso das desigualdades sociais, das desigualdades fundadas no preconceito, estabelecendo de forma cristalina o objetivo de promover a justiça social e a igualdade de tratamento entre os cidadãos. Este é, a meu ver, o sentido claramente concebido no art. $3^{\circ}$ da Constituição, quando inclui dentre os objetivos fundamentais da República promover o bem de todos, sem preconceitos de raça, sexo, cor, idade ou quaisquer outras formas de discriminação. (lbidem)

O Ministro, com essa fala, mostra que qualquer ato que gere exclusão ou privação a direitos, é um ato inconstitucional. Quando não se reconhece a união estável para os casais que detêm todos os requisitos para tanto, somente por sua sexualidade, sendo essa uma forma discriminatória vedada pela Constituição. Não há como falar em uma única forma de casal, principalmente diante da pluralidade que a modernidade traz.

Se a vida nas comunidades humanas revela, normalmente, um casal composto de homem e mulher, não é esta a única forma de vida, pois sempre existiram e podem se formar parcerias de homossexuais, suscitando dificuldades jurídicas, "mais frequentes e menos assumidas, permanecendo marginalizadas." (PEREIRA, 2001, p. 197)

O princípio da não discriminação, constante do art. $3^{\circ}$, IV, mencionado acima, foi objeto de grandes debates durante a Assembleia Nacional Constituinte. Em pelo menos 2 Subcomissões constava, na lista das hipóteses de vedação à discriminação, a "discriminação por orientação sexual"; no entanto, por pressão de constituintes evangélicos, tal expressão foi suprimida. De toda sorte, o responsável pela redação final do texto deixou claro em seu parecer que estava retirando a expressão porque a mesma já estaria contida na vedação 
à "discriminação por sexo" - ou, de qualquer forma, pela genérica "e outras formas de discriminação" (BAHIA; MORAES, 2012).

Sobre o princípio da igualdade é preciso que se compreenda que o mesmo não quer dizer apenas isonomia (igualdade formal) ou equidade (igualdade material), mas possui também uma terceira dimensão, isto é, a diversidade. No primeiro caso o indivíduo/grupo é tratado pelo Estado (e os particulares) desconsiderandose (sendo cego para) suas diferenças. É o que ocorre no caso do direito ao voto. No segundo caso, há outras hipóteses em que as diferenças são notadas para que sejam eliminadas ou pelo menos minimizadas. Políticas como as relativas a proteções trabalhistas estão nesse grupo. Ocorre que, em algumas outras hipóteses, fazse necessário perceber que há diferenças, mas que estas não serão enxergadas como um "mal”, mas como um componente normal da pluralidade humana. Daí se percebe que não se trata exatamente de "diferença" (que toma um referencial de normalidade como padrão), mas, sim, de "diversidade", isto é, de formas de vida igualmente legítimas (BAHIA, 2013). O reconhecimento de que há (de quem sempre houve) diversas orientações sexuais e identidades de gênero para além das respectivas binariedades "tradicionalmente reconhecidas" é fundamental para repensarmos categorias e institutos do direito que, da forma como estão, apenas podem ser compreendidos como privilégios, a menos que sofram aquela filtragem constitucional.

Saber quando se está diante de um caso de isonomia, equidade ou diversidade não é algo fácil. São os afetados pelas ações do Estado - por ações diretas ou por ações indiretas, como incentivos e vedações à ação de particulares - que poderão, discursivamente, expor e reivindicar as diferentes formas de igualdade. Nesse sentido a já célebre assertiva de Boaventura de Sousa Santos (2003, p. 458): "temos o direito a ser iguais quando a nossa diferença nos inferioriza; e temos o direito a ser diferentes quando a nossa igualdade nos descaracteriza". No caso do reconhecimento da união homoafetiva tem-se, num primeiro momento, a questão da diversidade de orientações sexuais, para, logo em seguida, vir a reivindicação por isonomia das relações afetivas.

Aprofundando a discussão, o Ministro relator Ayres Britto relaciona o princípio da liberdade com os direitos à intimidade e à privacidade, dizendo que:

[...] Mais ainda, liberdade que se concretiza: I - sob a forma de direito à intimidade, se visualizada pelo prisma da abstenção, ou, então, do solitário desfrute (onanismo); II - sob a forma de direito à privacidade, se a visualização já ocorrer pelo ângulo do intercurso ou emparceirado desfrute (plano da intersubjetividade, por conseguinte). 36. Não pode ser diferente, porque nada mais íntimo e mais privado para os indivíduos do que a prática da sua própria sexualidade. Implicando o silêncio normativo da nossa Lei Maior, quanto a essa prática, um lógico encaixe do livre uso da sexualidade humana nos escaninhos jurídico-fundamentais da intimidade e da privacidade das pessoas naturais. Tal como sobre essas duas figuras de direito dispõe a parte inicial do art. 10 da Constituição, verbis: "são invioláveis a intimidade, a vida privada, a honra e a imagem das pessoas". Com o aporte da regra da auto-aplicabilidade possível das normas consubstanciadoras dos direitos e garantias fundamentais, a teor do $\S^{\circ} \stackrel{\circ}{\text { do }}$ art. $5^{\circ}$ da nossa Lei Maior, assim redigido: "As normas definidoras dos direitos e garantias fundamentais têm aplicabilidade imediata". (BRASIL. Supremo Tribunal Federal. ADPF 132/RJ)

Nesse contexto, o Ministro demonstrou que não se pode ferir o direito a intimidade nem mesmo o da privacidade, e não há nada mais íntimo e privado que a sexualidade de um casal. O princípio da liberdade é um princípio fundamental que garante a intimidade e a privacidade. Sem disposição em contrário na 
Constituição Federal, não é possível diferenciar os casais baseando em sua sexualidade, não havendo, assim, ilicitude em um relacionamento homoafetivo.

Há de se ressaltar a pontuação do Ministro Luiz Fux que argumenta que a negativa ao reconhecimento da união homoafetiva não se traduz na proteção de nenhum bem jurídico para a sociedade, isto é, quando os casais homoafetivos perdem suas liberdades não há um ganho em nenhum outro dispositivo constitucional, na realidade, há somente perdas. É preciso ter em mente que a concepção majoritária de moral não é juridicamente obrigatória, mesmo que seus adeptos acreditem que o é (FONSECA, 2013). Tal fato é preciso ser pontuado: sendo a concessão do direito a "igual proteção" de um grupo frente aos demais incapaz de gerar danos a estes, não se sustenta qualquer argumento no sentido de se privar aquele grupo do tal direito. Se a maioria não perde qualquer direito quando tal é concedido a uma minoria, o que senão o preconceito, sustenta a discriminação?

O Ministro Relator Ayres Britto, discorrendo sobre a autonomia privada do indivíduo, afirma que a união homoafetiva é uma decorrência do princípio da dignidade da pessoa humana e expressão direta do direito à própria sexualidade, à livre orientação sexual, elevando esse fator ao patamar de cláusulas pétreas, nos termos do art. $60, \S 4^{\circ}$, inciso IV ${ }^{7}$, da Constituição Federal, dispositivo este que proíbe a abolição dos direitos e garantias individuais do seio constitucional.

O Ministro Marco Aurélio, em seu voto, ressaltou os reflexos que o princípio da dignidade da pessoa humana provocou no Direito Civil como um todo, inclusive no Direito de Família, onde a orientação prioritária passou do âmbito jurídico-patrimonial para o jurídico-existencial, diz ele que:

O Direito Civil, sabemos, restringia-se ao "ter". O titular da propriedade era o grande destinatário das normas do Direito Civil, e a propriedade era o direito por excelência. O direito de família oriundo do Código Bevilácqua concernia a questões patrimoniais. O Direito Civil, na expressão empregada por Luiz Edson Fachin, sofreu uma "virada de Copérnico", foi constitucionalizado e, por consequência, desvinculado do patrimônio e socializado. A propriedade e o proprietário perderam o papel de centralidade nesse ramo da ciência jurídica, dando lugar principal à pessoa. É o direito do "ser", da personalidade, da existência. (BRASIL. Supremo Tribunal Federal. ADPF $132 / \mathrm{RJ})$

A constitucionalização do Direito elevou os princípios constitucionais a norteadores da forma como os ramos do Direito devem ser aplicados. Assim, a dignidade da pessoa humana, bem como outros princípios normativo-constitucionais como a igualdade, a liberdade, a intimidade, etc. (apenas para citar alguns que nos interessam mais de perto no presente) tomam posição de ascendência sobre regras dos Direitos Civil, Penal, Tributário, etc. Qualquer que seja a área do Direito, a Constituição é a norma primeira a ser considerada ${ }^{8}$. No caso específico da citada "dignidade humana":

Um dos mais profundos reflexos provocados pela constitucionalização do Direito Civil consiste na proclamação do primado da dignidade da pessoa humana. Princípio expressamente consagrado pelo artigo 1ํㅡㄹ inciso III da Constituição da República, o reconhecimento desta dignidade coloca a pessoa humana no centro do ordenamento. O enfoque no Direito Civil, por consequência, passa do "ter" para o "ser", abandonando-se a visão formal do ser humano como mero detentor de direitos [...] (GODINHO, 2013, p. 4).

\footnotetext{
7 BRASIL, Constituição Federal. Art. 60. A Constituição poderá ser emendada mediante proposta: [...] § 4ํ- Não será objeto de deliberação a proposta de emenda tendente a abolir: [...] IV - os direitos e garantias individuais.

8 O fenômeno da constitucionalização do direito ocorre na Europa pós-2a Guerra; no entanto, apenas se verificará no Brasil com a atual Constituição. (BAHIA, 2012)
} 
O Ministro Luiz Fux traz para o debate a ideia de uma política de reconhecimento, que é fruto do princípio da dignidade da pessoa humana, política essa que ultrapassa o sentido formal de igualdade para que seja reconhecido como legítima e digna de respeito e proteção todas as diferenças entre os seres humanos:

A aplicação da política de reconhecimento dos direitos dos parceiros homoafetivos é imperiosa, por admitir a diferença entre os indivíduos e trazer para a luz relações pessoais básicas de um segmento da sociedade que vive parte importantíssima de sua vida na sombra. Ao invés de forçar os homossexuais a viver de modo incompatível com sua personalidade, há que se acolher a existência ordinária de orientações sexuais diversas e acolher uma pretensão legítima de que suas relações familiares mereçam o tratamento que o ordenamento jurídico confere aos atos da vida civil praticados de boa-fé, voluntariamente e sem qualquer potencial de causar dano às partes envolvidas ou a terceiros. Ressalte-se este último ponto: uma união estável homoafetiva, por si só, não tem o condão de lesar a ninguém, pelo que não se justifica qualquer restrição ou, como é ainda pior, a limitação velada, disfarçada de indiferença. (BRASIL. Supremo Tribunal Federal. ADPF 132/RJ)

Ao reconhecer, retira-se a valorização negativa de determinada identidade, sendo necessário eliminar a necessidade de o cidadão provar, a todo o momento, que é detentor de tal isonomia nas relações sociais. Sobre isso, o Ministro Joaquim Barbosa disserta que:

O reconhecimento dos direitos das pessoas que mantêm relações homoafetivas decorre, a meu sentir, do acolhimento no nosso sistema jurídico do postulado ou da ideia de reconhecimento, uma emanação do princípio da dignidade humana, tema sobre a qual vem se debruçando toda uma linhagem de ilustres autores nacionais e estrangeiros. Toda essa temática, aliás, vem do Multiculturalismo, do pensamento diferencialista, da noção de que todos, sem exceção, têm direito a uma igual consideração [...]. (Ibidem)

O Ministro mostra, com esses dizeres, a necessidade que o sistema jurídico tem de acolher as minorias, no caso em tela, os casais homoafetivos, para que haja uma real adequação ao princípio da dignidade da pessoa humana, para que não haja diferenciação entre as pessoas. Ao igualarmos as pessoas, ao invés de diferenciarmos elas, não possibilitamos que haja um discurso de exclusão, não havendo a propagação do discurso "Nós x Eles"9. Assim, todos seriam seres humanos e cidadãos iguais mesmo que diferentes. A pluralidade não deve ser um fardo na sociedade moderna, mas sim deve ser um fato, e como tal, deve ser incorporada ao sistema jurídico pátrio.

O reconhecimento da diversidade é uma expressão, melhor dizendo, uma exigência do pluralismo, cujo fundamento de convivência política se coaduna na tolerância recíproca. O sistema jurídico deve garantir e valorizar as várias formas de pensamento e de conduta existentes, não permitindo a discriminação nem a opressão de grupos sociais. O Estado não deve incentivar uma cultura dominante em detrimento as demais, não pode ser uma ferramenta para a uniformização da sociedade, ao contrário, deve ser uma ferramenta para garantir sua pluralidade. Sobre o pluralismo social e político (Art. 1ํ, V, CF), a Ministra Carmen Lúcia esclarece em seu voto que:

\footnotetext{
9 “[...] o que fundamenta a lógica "nós x eles", sobre a qual se constrói a modernidade, é o "fato" de que "eles" não são iguais a "nós". "Eles" não têm alma ou são animalizados ou coisificados." (MAGALHÃES, 2012, p. 28). O mesmo autor em seguida explica que a lógica é que "nós" somos os superiores, os mais belos, os mais inteligentes, os mais sábios, etc., enquanto "eles" são os inferiores, os feios, os sem inteligência, etc., desta forma, se justifica coisificar ou animalizar o outro, uma vez que ele não é como nós e por isso não merece o mesmo tratamento.
} 
Considero o pluralismo político também uma expressão que se estende além dos limites da atividade política ou do espaço político. Bem ao contrário, tenho que o pluralismo haverá de ser social para se expressar no plano político. E o pluralismo social compõe-se com a manifestação de todas as opções livres dos indivíduos, que podem viver segundo suas tendências, vocações e opções. Daí a escolha da vida em comum de duas pessoas do mesmo sexo não poder ser tolhida, por força de interpretação atribuída a uma norma legal, porque tanto contrariaria os princípios constitucionais que fundamentam o pluralismo político e social [...]. (Ibidem)

Sobre a interpretação do artigo 226, $3^{\circ}$ da Constituição Federal Luiz Fux disserta que:

A norma foi inserida no texto constitucional para tirar da sombra as uniões estáveis e incluí-las no conceito de família. Seria perverso conferir à norma de cunho indiscutivelmente emancipatório interpretação restritiva, a ponto de concluir que nela existe impeditivo à legitimação jurídica das uniões homoafetivas, lógica que se há de estender ao art. 1.723 do Código Civil. Urge, pois, renovar esse mesmo espírito emancipatório e, nesta quadra histórica, estender a garantia institucional da família também às uniões homoafetivas [...]. (Ibidem)

As interpretações do artigo 226, §3º da Constituição Federal e do artigo 1.723 do Código Civil, segundo os Ministros Celso de Mello e Luiz Fux, devem ser feitas de forma extensiva, possibilitando a inclusão do máximo possível de situações, não podendo ser interpretados como forma de excluir uma parcela da população.

Insista-se, para que não haja margem a dúvida: não tem pertinência a invocação do argumento de que o emprego da expressão "união estável entre o homem e a mulher" importa, a contrario sensu, em proibição à extensão do mesmo regime a uma outra hipótese. Tal norma foi o ponto culminante de uma longa evolução que levou à equiparação entre companheira e esposa. Nela não se pode vislumbrar uma restrição - e uma restrição preconceituosa - de direito. Seria como condenar alguém com base na lei de anistia. O Código Civil, por sua vez, contém apenas uma norma de reprodução, na parte em que se refere a homem e mulher, e não uma norma de exclusão. Exclusão que, de resto, seria inconstitucional. (BARROSO, 2009. p. 208-209)

Excluir, no caso, não apenas vai contra o já citado art. $3^{\circ}$, IV, mas também nega o caráter aberto de uma Constituição, algo que, no nosso caso, está previsto textualmente quando o $\S 2^{\circ}$ do art. $5^{\circ}$ preceitua que o (extenso) rol de Direitos Fundamentais contido no texto não é taxativo, mas aberto, uma vez que não se exclui que outros possam ser incorporados, seja via Tratados e Convenções Internacionais, seja mesmo através da interpretação do que já ali se encontra. Pensar que a Constituição teria "fixado" um modelo apenas de união estável vai contra o objetivo do que é uma Constituição ${ }^{10}$ : ela é um texto criado para garantir e não para limitar direitos; é um texto vivo (living constitution) que deve estar aberto para novos direitos e novos sujeitos de direitos, quer tenham seus idealizadores querido ou não incluir este ou aquele grupo quando a redigiram.

O entendimento dos Ministros foi pela procedência do pedido; os argumentos de maior relevância foram trazidos para um melhor entendimento de como ocorreu a fundamentação da decisão final.

\section{Metodologia de Castanheira Neves: o jusprudencialismo}

É importante entender a decisão jurídica para se entender o direito. Sabendo isto, Castanheira Neves se debruçou sobre elas para compreendê-las. Baseando na hermenêutica filosófica (Gadamer) e na filosofia hermenêutica (Heidegger), Neves apresenta uma concepção jurisprudencialista do direito, tendo pensado em uma metodologia de interpretação jurídica.

\footnotetext{
${ }^{10}$ Aliás, vai contra, inclusive a construção frasal, já que em nenhum momento está dito que "somente se reconhece" como união estável o formato $\mathrm{X}$ ou $\mathrm{Y}$.
} 
Castanheira Neves (1998) explica que o direito é a realização prática, é uma experiência jurídica prática, apresentando uma concepção jurisprudencialista de direito, opondo-se, dessa forma, tanto ao positivismo jurídico, quanto ao funcionalismo sociológico. Neves apresenta uma concepção de direito que tem como núcleo a decisão jurídica e que busca resgatar os princípios axiológicos materiais no âmbito dos problemas práticos. Em sua teoria, o direito deixa de ser um mero instrumento do poder, não sendo também um meio para consecução de finalidades estratégicas, passando a ser uma questão de validade que está além do positivismo jurídico, estando na dimensão de uma responsabilidade ética comunitária.

É necessário acrescentar que a concretização da lei de forma fria, apoiada pela mera exegese, além de não poder atender as expectativas da população frente à necessidade de adequação hábil às mudanças sociais, [...], provocou a necessidade de alargamento da razão jurídica o que culminou com a crise no positivismo jurídico, ou seja, o direito acaba tendo que demonstrar autonomia frente à lei para poder atender de forma satisfatória as demandas trazidas a sua apreciação, em contraposição à simples correlação da identificação com a legislação. Ademais, não se pode esquecer que a afirmação dos direitos fundamentais foi responsável pela imperativa necessidade de abertura interpretativa. (SILVA, 2013, p. 144)

A metodologia criada por Castanheira Neves pressupõe uma superação do estilo de interpretação e decisão jurídica positivista. Pressupõe um "(re)ver que é sempre uma tarefa difícil porque implica um certo abandono de princípios, implica também um (re)construir" (CURI, 2005, p. 849).

O esforço teórico de Castanheira Neves foi com o objetivo de encontrar e justificar a autonomia do direito em relação à política, de forma a ultrapassar uma justificação formal. Sendo necessário encontrar uma justificação material, axiológica, da validade do direito, tendo como meta justificar o direito através de uma justificação transpositiva e supralegal da normatividade jurídica do direito. Com isso, o direito não mais pode ser concebido somente como sendo um instrumento das políticas públicas do Estado, passando a ser visto como "uma entidade humano-cultural e prática muito específica em que o próprio sentido da prática humana se comprometia" (NEVES, 2003, P. 104). A partir de então, o problema do direito deixou de ser apenas um problema da sua legitimidade política, passando a ser um fundamento da validade material constitutiva do direito. O direito passa a ser algo maior e mais fundamental que a legalidade, tornando, assim, o jus para além da lex (NEVES, 2002).

Castanheira Neves (1993) explica ainda que a problematicidade dos casos concretos de cada época e a intenção normativa material do direito de cada comunidade influenciam o próprio desenvolvimento metodológico de interpretação, argumentação e decisão jurídica, sendo necessário compreender a metodologia jurídica em uma perspectiva ampla, tornando capaz de assimilar o sentido da problemática concreta do direito e a sua intenção normativa material.

Para Castanheira Neves (1995), a metodologia jurídica não mais pode se ater a ser uma técnica de aplicação do direito, menos ainda presumir que o direito são as leis. A decisão jurídica não pode ser vista como mera aplicação da lei, devendo ser interpretada como sendo o momento no qual o direito é criado e realizado. Para ele (1993), o decisor jurídico não é um concretizador do direito abstrato criado pelo legislador, menos ainda, o legislador é um antecipador abstrato da concretização do direito realizada pelo decisor. 
Uma coisa é a prescrição legislativa, com um enquadramento jurídico, mas com uma institucional e funcional índole político-social numa intenção estratégica e programaticamente reformadora ou organizadora, outra coisa a realização do direito, com momentos normativo-juridicamente constitutivos, mas de índole institucional e funcionalmente judicativo-decisória e uma intenção de concreto cumprimento da normativa validade jurídica. (NEVES, 1993, P. 21)

A metodologia jurídica proposta por Castanheira Neves (1993, P. 30) seria "uma mediação normativojurídica própria da concreta realização do direito", ou seja, uma metodologia de mediação entre a normatividade do direito positivo e a normatividade dos demais princípios e valores sociais que levam ao entendimento da decisão jurídica.

A decisão jurídica ocorre quando o julgador encontra uma norma jurídica capaz de servir de critério, na mediação, entre o sistema e o problema, mas aí surge a questão: Como realizar adequadamente essa mediação? Essa é a pergunta que Castanheira Neves tenta responder ao criar sua metodologia de interpretação das decisões jurídicas. O estudioso renuncia à ideia positivista da mera subsunção entre a descrição do fato e a descrição da norma, que procura normas que possam atuar no fato. Ele visualizou que, por vezes, é necessário fazer ajustes no entendimento da norma para que ela se aplique ao fato concreto, fazendo uma assimilação dialética entre o sistema e o problema.

Há entre sistema e problema uma relação dialética. Pode-se dizer que a normatividade está estabilizada em função das perguntas ou interrogações dirigidas do problema para o sistema, no entanto, novos problemas colocam novas perguntas ou revelam a inadequação de velhas respostas. Os novos problemas fazem emergir novas intenções (valores, princípios), que relativizam as intenções anteriormente estabelecidas, trazendo consigo a exigência de ordenálas de tal forma que constituam um todo congruente. (SILVESTRE, 2007, p. 17.)

A mediação pela norma hipoteticamente aplicável ocorre partir da confrontação entre o sistema (intencionalidade da norma jurídica) e o problema (âmbito de relevância jurídica do problema do caso concreto). Através dessa confrontação podem surgir três possíveis situações: (1) uma correspondência linear entre a ideia da norma e a relevância do problema; (2) uma correspondência parcial, que pode ser reajustada por adaptação ou por correção; ou (3) a inexistência de correspondência, sendo necessária que a decisão seja construída autonomamente. Existindo uma correspondência linear, a decisão jurídica torna-se simples, basta comprovar a existência da linearidade entre o sistema e o problema. Se houver uma correspondência parcial, a decisão jurídica deve ajustar, por adaptação ou correção, o sistema ao problema. Se não existir nenhuma correspondência, a decisão jurídica deve-se fundamentar nos princípios (NEVES, 1993). No caso de correspondência parcial, a decisão jurídica deve utilizar de analogia para solucionar o problema. A analogia pode ser extensiva ou restritiva. A extensiva ocorre quando a problemática do caso está aquém do âmbito de relevância da norma, já a restritiva ocorre quando o problema do caso extrapola ao âmbito de relevância da norma.

Castanheira Neves (2003) explica que para se conseguir uma decisão jurídica correta ao direito, devese ter uma atenção especial aos princípios. Eles não mais podem ser entendidos como axiomas que garantem a completude do sistema no caso de lacuna, mas devem ser entendidos como princípios normativos materiais, que fundamentam o próprio direito. Assim, eles não conferem apenas racionalidade ao sistema, eles conferem sentido ao mesmo. 
Os princípios são fundamentos que determinam a intencionalidade da normatividade global do direito, que determina o "espírito" do sistema jurídico, são eles que determinam todo o sistema jurídico. Os princípios podem estar positivados, ou não. Se eles não estiverem positivados, podem ser princípios transpositivos ou suprapositivos. Independente do caso, os princípios são pressupostos fundamentais do sistema, e, por isso, a decisão jurídica quando tiver de assimilar, por adequação ou por correção, deve operar a assimilação em conformidade com os princípios (NEVES, 2002). Os princípios positivos são os princípios que estão positivados de forma expressa no texto normativo em vigor. Os princípios transpositivos são os que estruturam e organizam a ordem jurídica positiva, sendo eles transcendentais à ordem jurídica positiva, estando além do direito positivo. Já os princípios suprapositivos são os que se encontram acima dos princípios positivos, são os que definem os elementos e categorias do sentido último do direito (NEVES, 2003). As leis podem permanecer inalteradas em seus textos e suas descrições semânticas, mas os princípios e os valores normativos são dinâmicos. Os princípios mudam junto com a sociedade, possibilitando, assim, que haja uma atualização do sentido das normas positivadas.

Podem ocorrer situações onde não há correspondência entre a questão de fato e a questão de direito. Nesses casos, a decisão jurídica deverá assimilar a intencionalidade do sistema e o problema sem a mediação de normas jurídicas, recorrendo a outros critérios e fundamentos do direito. Mas essa ausência de normas previamente existentes no sistema para o caso concreto não significa que a decisão jurídica pode criar qualquer critério, não significa um vazio, onde pode ser decidido de qualquer forma. Existem critérios normativos transpositivos que a decisão jurídica deve respeitar. A intencionalidade do direito constitui limites à criatividade da decisão jurídica, não podendo o juiz deixar de decidir (non liquet): nos casos de lacuna a decisão deve criar o direito para solucionar o problema. Mas essa criação tem de estar em conformidade com o projeto intencional do direito, sendo fundamentado em princípios (NEVES, 1993).

Após entender a importância dos princípios para a teoria de Castanheira Neves (1993), há um ponto imprescindível a ser abordado: o critério que deve ser utilizado para o entendimento da decisão jurídica, que, para ele, é a analogia. A analogia é um argumento retórico que estabelece uma conexão entre duas coisas mediante a comparação, mediante a análise da correspondência, semelhança e proporção entre as coisas. A analogia não possui um controle lógico nem mesmo um controle empírico. É uma operação muito mais intuitiva que indutiva ou dedutiva, e, por isso, necessita de um objetivo, um critério e um fundamento ${ }^{11}$. O objetivo é o caso concreto, o critério é a analogia e o fundamento é a consciência jurídica geral. A consciência jurídica geral é a intencionalidade normativa do direito; corresponde à intencionalidade axiológica da comunidade a qual se faz parte, sendo a autocompreensão fundamental e originária do homem em sua humanidade (NEVES, 2002). A consciência jurídica geral é pontual e deriva de processo histórico-momentâneo da sociedade em questão. Em suma, é a síntese de todos os princípios e valores normativos que uma comunidade entende como fundamental. É a síntese "axiológico-jurídica dessa comunidade" (NEVES, 1993, p. 280)

Na metodologia de Castanheira Neves (1993), a decisão jurídica não pode ser somente normativamente fundamentada, mas deve também ser socialmente justificada. Isso porque uma decisão não se torna irracional

\footnotetext{
${ }^{11}$ Um objeto é constituído de elementos a ser relacionados ou comparados, um critério opera para a construção da identidade e das distinções que ela faz e o fundamento é a justificativa do critério.
} 
só por conta de seus efeitos, não podem ser racionalizados economicamente por irem contra as políticas públicas do governo. A decisão jurídica está na sua justificação normativa e não na sua justificação empírica, tendo como base as consequências da decisão. As únicas consequências que devem ser levadas em consideração são as consequências jurídicas, ou seja, qual será o impacto que ela produzirá na coerência jurisprudencial e doutrinária do sistema.

Com a metodologia criada por Castanheira Neves, abre-se uma forma diferente (do que usualmente se tem nos tribunais do Brasil, mas com grande respeitabilidade no meio acadêmico) para se interpretar a decisão da ADPF 132 e da ADI 4.277.

\section{Interpretação da decisão jurídica pela metodologia de Castanheira Neves}

Cada época tem seus dilemas sociais que refletem, consequentemente, no sistema jurídico. A questão da família é um tema sempre recorrente na história das discussões jurídicas, porque o conceito de entidade familiar sempre foi restritivo e impositivo. Um exemplo dessas discussões, no passado, foi sobre o casamento entre pessoas de "raças" distintas, ou seja, entre brancos e negros; atualmente a discussão volta-se para o reconhecimento, ou não, das relações homoafetivas como sendo uma entidade familiar. A ADPF 132 e a ADI 4.277 visaram solucionar esse problema.

Para entender como ocorreu o julgamento dessas duas ações, vamos utilizar a metodologia criada por Castanheira Neves. Para utilizar tal metodologia, deve-se ter em mente que a metodologia jurídica não é uma técnica de aplicação do direito, tampouco o direito é a lei positivada. Desta maneira, a decisão jurídica não é a mera aplicação da lei ao caso concreto, mas é o momento no qual o direito é criado e realizado. A decisão jurídica é a mediação entre o direito positivo e os princípios e valores da sociedade.

Nos casos em tela, a norma é restritiva, sendo esse o problema jurídico: a norma tem um âmbito de abrangência restritivo às possibilidades existentes. O artigo 1.723 do Código Civil de 2002 traz que: "É reconhecida como entidade familiar a união estável entre o homem e a mulher, configurada na convivência pública, contínua e duradoura e estabelecida com o objetivo de constituir família.". À primeira vista, interpretando de forma literal o referido artigo, somente se pode ter união estável entre homem e mulher, qualquer outra forma distinta desta não seria válida juridicamente, sendo considerada entidade familiar somente essa formação familiar. Mas é essa interpretação literal que Castanheira Neves ensina que não se pode fazer, pois interpretando dessa forma, as normas não conseguiriam suprir as necessidades da sociedade.

Ao vislumbrar o problema da legitimação jurídica das uniões homoafetivas, foram propostas as referidas ações. Para a solução do problema pelo sistema, houve a necessidade da utilização da interpretação do artigo conforme os princípios fundamentais da sociedade consubstanciados na Constituição. Os princípios, ao conferirem racionalidade e sentido ao sistema, devem sempre ser levados em consideração na decisão jurídica. Foi necessário adequar a norma aos princípios que fazem parte da consciência jurídica geral, ou seja, a norma teve de ser adequada à autocompreensão jurídica da comunidade.

Muitos princípios foram analisados antes do proferimento da decisão final. Os mais importantes foram os princípios da igualdade, da liberdade, da dignidade da pessoa humana, da segurança jurídica e da vedação 
a discriminação odiosa. Sendo eles dinâmicos, devem ser utilizados para atualizar as normas positivadas. A decisão deve estar em conformidade com o projeto intencional do direito, que é fundamentado pelos princípios.

Levando-se em consideração a metodologia da construção da decisão jurídica de Castanheira Neves, o objeto da decisão jurídica é a equiparação da união homoafetiva com a união estável, o critério é a analogia e o fundamento a consciência jurídica geral. Por analogia, quando o Código Civil fala que reconhece a união estável entre homem e mulher, está possibilitando que haja variações, como entre homens ou entre mulheres. Tal "limitação" trazida pelo Código Civil tem um caráter exemplificativo, ou seja, não se pode ter uma união estável entre três, quatro ou cinco pessoas, pois a poligamia não é aceita pelo sistema jurídico, tampouco pode haver esse tipo de união entre seres humanos e outros animais. É o que ocorre, por exemplo, em uma Convenção de Condomínio onde se proíbe a entrada de cães e, por analogia, é possível perceber que não é possível a entrada de gatos, ursos, cavalos etc. Assim, a norma proíbe a entrada de animais de estimação, e não apenas cães ${ }^{12}$. O mesmo ocorre com o artigo 1.723 quando interpretado por analogia. $O$ referido artigo reconhece a união estável entre casais de seres humanos (formados por 2 pessoas), não necessariamente sendo esses casais compostos por um homem e uma mulher. Barroso (2007, P. 2) nos adverte que: "[...] quando não fosse uma imposição do texto constitucional, a equiparação de regimes jurídicos decorreria de uma regra de hermenêutica: na lacuna da lei, deve-se integrar a ordem jurídica mediante o emprego da analogia.".

Mas não é possível utilizar a analogia e chegar a um resultado sem que o mesmo esteja em conformidade com a consciência jurídica geral da comunidade. Assim, podemos lembrar que a sociedade está cada dia mais plural, não aceitando que haja qualquer tipo de discriminação, tanto que a proibição da discriminação ao diferente ganhou caráter constitucional (Art. 3ํ, IV).

A sociedade não coaduna com nenhum tipo de discriminação. A autocompreensão jurídica da comunidade vislumbra o direito ao tratamento igualitário entre as pessoas. Desta maneira, uma decisão jurídica que promova discriminação ou desigualdade entre as pessoas não é socialmente justificada. Lembrando que a decisão jurídica sempre deve ser socialmente justificada. A decisão dos Ministros do Supremo Tribunal Federal, ao ser interpretada através da metodologia de Castanheira Neves, mostra-se acertada, uma vez que, mesmo existindo pessoas contrárias a esse tipo de relacionamento, a sociedade em geral o entende como sendo um relacionamento válido, pois se trata de dois seres humanos.

Complementarmente, procuram-se as raízes da ideia de família (e sua mutalibilidade) a partir de uma leitura hermenêutica do instituto: se família hoje está ligada à afetividade e não mais a propriedade/poder/procriação, então o que diferenciaria uma família heteroafetiva ou homoafetiva? A partir daí se busca, desde os rudimentos da hermenêutica clássica até a sofisticação da hermenêutica gadameriana, mostrar que a interpretação conforme a Constituição operada pelo STF não constitui uma corrupção/traição ao texto constitucional, mas, ao contrário, respeita ao mesmo em sua interpretação sistemático-teleológica. Busca-se refutar argumentos que tradicionalmente se levantam contra o reconhecimento da união homoafetiva e mostra que nenhum deles se sustenta perante a Constituição. (BAHIA; VECCHIATTI, 2013, p. 66.)

\footnotetext{
12 De toda sorte, apenas para acrescentar mais um elemento à discussão, perceba-se que, se no condomínio residir uma pessoa portadora de deficiência visual e que tenha um cão-guia, estaria este animal proibido de entrar com seu dono mesmo que a Convenção nada tenha trazido sobre o tema? Conceber que a literalidade do texto "é proibido entrar no Condomínio com cães" faria com que o morador conteria também uma proibição ao morador cego seria pensar o Direito de forma muito "pobre".
} 
Toda decisão jurídica gera consequências no sistema e estas devem ser levadas em consideração. A cada decisão jurídica alteram-se, em alguma medida, a jurisprudência e a doutrina. Ao equiparar a união homoafetiva à união estável, conferindo status de entidade familiar, a decisão jurídica alterou o sistema (ou consolidou, agora com efeito vinculante, uma alteração que já vinha se operando na jurisprudência e doutrina).

Nota-se, portanto, que tendo sido declarada a união homossexual como um modo de união estável, conseqüências são geradas em diversos campos. [...] Os tribunais passaram a notar a injustiça que cometiam não permitindo a partilha de bens, o direito a benefícios previdenciários, entre outros, apenas por falta de normas legais e passaram a analisar as relações homossexuais como "sociedade de fato", ou seja, começaram a entender que se tratava de uma reunião de duas pessoas que reciprocamente se obrigam a contribuir, com bens ou serviços, para o exercício de atividade econômica e a partilha, entre si, dos resultados. (BATISTA, 2013, p.10)

A Constituição Federal de 1988, em seu artigo 226 traz que: "A família, base da sociedade, tem especial proteção do Estado". O caput do referido artigo já mostra toda a preocupação que o constituinte teve com a questão familiar, consagrando a família como base da sociedade, e por isso conferindo uma proteção especial por parte do Estado. O mesmo artigo em seu parágrafo terceiro traz que: "Para efeito da proteção do Estado, é reconhecida a união estável entre o homem e a mulher como entidade familiar, devendo a lei facilitar sua conversão em casamento". Ou seja, já que a família é a base da sociedade, o Estado reconheceu como entidade familiar a união estável e, ao mesmo tempo, propôs a facilitar a transformação da união estável em casamento.

A discussão sobre a possibilidade de haver união estável homoafetiva, bem como o casamento civil homoafetivo não é nova. Desde 1989 vários países europeus vêm discutindo e adotando legislação cujo foco é a "parceria civil" e o casamento entre pessoas com o mesmo sexo (BAHIA; MORAES, 2012), mostrando que esse tema já é visto como relevante há algum tempo, mas somente agora chegou ao STF. Essa morosidade para discutir o tema é reflexo direto da inércia do legislativo, que não deseja discutir temas fraturantes, principalmente quando há uma minoria necessitando de ser representada (BAHIA; NUNES, 2010).

Com isso, a decisão jurídica proferida pelo Supremo Tribunal Federal, reconhecendo a união homoafetiva como união estável, consequentemente, conferindo a ela o caráter de entidade familiar, garante a possibilidade de transformar essa união em casamento civil. Mais que isso, faz com que o Estado deva facilitar que ocorra a conversão da união estável (homoafetiva) em casamento. Mesmo os Ministros não entrando no cerne dessa questão, ao conferirem o caráter de entidade familiar já possibilitaram a conversão de tal união em casamento.

Castanheira Neves diz que a decisão jurídica não deve levar em consideração nenhuma outra repercussão, a não ser a repercussão jurídica. Ao igualar a união homoafetiva à união estável, houve reflexo em todo o direito, principalmente no direito de família, sendo irracional pensar que tal decisão somente garantiria o direito ao reconhecimento da união estável para os casais homoafetivos, sem nenhum tipo de reflexo nos demais direitos matrimoniais.

Ao decidirem de forma unânime, os Ministros do Supremo Tribunal Federal mostraram que estão atentos aos princípios que regem a sociedade brasileira e que também estão fazendo o papel contramajoritário, evitando a discriminação e a criação de cidadãos de "segunda categoria". Dessa forma, resta acertada a decisão das ações que visam igualar as uniões homoafetivas com as uniões estáveis. Com essa decisão, as 
uniões homoafetivas ganham um caráter de entidades familiares, sendo, então, permitido a esse tipo de casal ter um casamento civil.

\section{Considerações finais}

A decisão jurídica criada pela discussão da ADPF 132 e da ADI 4.277 alterou a visão de família no sistema jurídico brasileiro, bem como permitiu a visualização de uma forma de discriminação que até pouco tempo era ignorada. Com essa decisão jurídica foram igualados os direitos dos homossexuais aos dos heterossexuais, impossibilitando que haja uma distinção entre eles, distinção essa que pode ser vista como sendo discriminatória e criadora de uma gama de cidadãos de "segunda categoria", o que é vedado pela Constituição Federal, bem como pelos princípios jurídicos brasileiros.

Ao interpretar a decisão jurídica das ações em tela, verifica-se que houve acerto dos Ministros em conceder de forma unânime a procedência do pedido da ação. Isso porque tal resultado condiz com a consciência jurídica geral da sociedade brasileira. Para chegarem a esse resultado, os Ministros ponderaram vários princípios e, utilizando a analogia, vislumbraram que não poderia ter distinção jurídica movida somente pela questão sexual.

A decisão jurídica construída nas referidas ações consolidou (porque vinculantes as decisões) uma mudança da forma como se compreende família. Com isso, surgiram várias dúvidas jurídicas, como se, a partir da decisão do STF, decorre a possibilidade de casamento civil entre pessoas do mesmo sexo.

A decisão jurídica sempre causa efeitos no sistema jurídico e, portanto, antes de proferir a decisão, o magistrado os deve levar em conta. Sendo assim, ao equipararem a união homoafetiva à união estável, reconhecendo a união homoafetiva como entidade familiar, os Ministros conferiram aos casais homoafetivos todos os direitos que tal decisão traz. Como por exemplo, a possibilidade de casamento civil, pensão por morte, guarda dos filhos, etc.

A possibilidade de casamento civil de casais homoafetivos é garantida quando se equipara as uniões homoafetivas com as uniões estáveis, pois confere, assim, a união homoafetiva status de entidade familiar, e sendo a família a base da sociedade, como nos traz a Constituição, ela deve ser protegida. A própria Constituição dispõe que compete ao Estado brasileiro facilitar a conversão da união estável em casamento civil. Ao equiparar tais uniões, gera uma nova obrigação ao Estado, que é a de facilitar a transformação da união homoafetiva em casamento, buscando proteger a família. Desta forma, ao vislumbrar a união homoafetiva como entidade familiar, garante também a esse tipo de união, o direito de ser protegido.

Essa decisão jurídica é ampla e a discussão dos efeitos gerados por ela ainda está longe de terminar, mas o que não podemos aceitar é que seja possibilitada a criação de cidadãos de segunda categoria, excluindo parte da população, mesmo que minoria, de direito básicos, como a proteção a família. 


\section{Referências}

BAHIA, Alexandre; MORAES, Daniel. O Longo Caminho contra a Discriminação por Orientação Sexual no Brasil no constitucionalismo pós-88: igualdade e liberdade religiosa. Revista Mandrágora, v. 18, p. 5-25, 2012.

BAHIA, Alexandre; VECCHIATTI, Paulo Roberto lotti. ADI n. 4.277 - constitucionalidade e relevância da decisão sobre união homoafetiva: O STF como instituição contramajoritária no reconhecimento de uma concepção plural de família. Revista Direito GV, São Paulo, jan./jun., 2013, p. 65-92.

BAHIA, Alexandre; NUNES, Dierle. Crise da democracia representativa - infidelidade partidária e seu reconhecimento judicial. Revista Brasileira de Estudos Políticos, n. 100, p. 57-83, jan./jun. 2010.

BAHIA, Alexandre. Fundamentos de Teoria da Constituição: a dinâmica constitucional no Estado Democrático de Direito brasileiro. In: FIGUEIREDO, Eduardo Henrique Lopes (et al) (Orgs.). Constitucionalismo e Democracia. Rio de Janeiro: Elsevier, 2012, p. 101-126.

BAHIA, Alexandre. A Igualdade é Colorida: por uma nova compreensão do direito de igualdade que reconheça o direito à diversidade In: ALVES, Cândice L.; MARCONDES, Thereza C. B. Bittencourt (orgs.). Liberdade, Igualdade e Fraternidade: 25 anos da Constituição Brasileira. Belo Horizonte: D'Plácido, 2013, p. 307-327.

BARROSO, Luís Roberto. Diferentes, mas iguais: o reconhecimento jurídico das relações homoafetivas no Brasil. Revista Diálogo Jurídico, n.16, mai/ago, Salvador, 2007.

BARROSO, Luís Roberto. Temas de Direito Constitucional. Tomo IV. Rio de Janeiro: Renovar, 2009.

BATISTA, Vanessa Oliveira. Legislação, seguridade social e casais do mesmo sexo no Brasil: uma evolução jurisprudencial. Revista Libertas UFOP, v. 1, n. 1, jan./jun., 2013.

CURI, Ivan Guérios. Virada de Copérnico: reflexão em torno do pensamento de A. Castanheira Neves. Boletim da Faculdade de Direito de Coimbra. Coimbra: Universidade de Coimbra, v. LXXXI, 2005.

DWORKIN, Ronald. O Império do Direito. São Paulo: Martins Fontes, 1999.

FONSECA, Letícia de Assis. A função contramajoritária do Supremo Tribunal Federal: Análise da decisão que equiparou a união homoafetiva à união estável (ADPF 132 e ADI 4.277). Brasília: Uniceub, 2013.

GODINHO, Adriano Marteleto. O fenômeno da constitucionalização: um novo olhar sobre o Direito Civil. Revista Libertas UFOP, v. 1, n. 1, jan./jun., 2013.

MAGALHÃES, José Luiz Quadros de. O Estado Plurinacional e o Direito Internacional moderno. Curitiba: Juruá, 2012.

NEVES, A. Castanheira. A crise actual da filosofia do direito no contexto da crise global da filosofia: tópicos para a possibilidade de uma reflexiva reabilitação. Coimbra: Universidade de Coimbra, 2003.

NEVES, A. Castanheira. Entre o "legislador", a "sociedade" e o "juiz" ou entre "sistema", "função" e "problema": os modelos actualmente alternativos da realização jurisdicional do direito. Boletim da Faculdade de Direito de Coimbra. Coimbra: Universidade de Coimbra, v. LXXXIV, 1998.

NEVES, A. Castanheira. Metodologia jurídica: problemas fundamentais. Coimbra: Coimbra Editora, 1993.

NEVES, A. Castanheira. O actual problema metodológico da realização do direito. in: Digesta: escritos acerca do Direito, do Pensamento Jurídico, da sua Metodologia e Outros. Coimbra: Coimbra Editora, 1995, v. 2, pp. 249-282. 
NEVES, A. Castanheira. O direito hoje e com que sentido? O problema actual da autonomia do direito. Lisboa: Instituto Piaget, 2002.

PEREIRA, Caio Mário da Silva. Direito Civil: alguns aspectos da sua evolução. Rio de Janeiro: Forense, 2001.

SANTOS, Boaventura de Sousa. Por uma concepção multicultural de direitos humanos. In: SANTOS, Boaventura de Sousa (Org). Reconhecer para libertar: os caminhos do cosmopolitismo cultural. Rio de Janeiro: Civilização Brasileira, 2003, p. 429-461.

SILVA, Allan Tones Andreza. O conceito de direito na perspectiva jurisprudencial de Castanheira Neves.

Revista A Barriguda, v. 3, n. 1, p.139-152, 2013.

SILVESTRE, Ana Carolina de Faria. Interpretação jurídica como um momento metodológico da realização do direito, segundo a perspectiva de Castanheira Neves. Revista da Faculdade de Direito do Sul de Minas, v. 25, n. 1, p. 1-20, 2007. 